\title{
Thermostability of the coating, antigen and immunostimulator in an adjuvanted oral capsule vaccine formulation
}

\author{
Stephanie Longet \\ Trinity College Dublin, Ireland \\ Vincenzo Aversa \\ Dublin City University \\ Daire O'Donnell \\ Technological University Dublin
}

See next page for additional authors

Follow this and additional works at: https://arrow.tudublin.ie/nanolart

Part of the Medicinal-Pharmaceutical Chemistry Commons, and the Pharmacy and Pharmaceutical Sciences Commons

\section{Recommended Citation}

Stephanie Longet, Vincenzo Aversa, Daire O’Donnell, Joshua Tobias, Monica Rosa, Jan Holmgren, Ivan S. Coulter, Ed C. Lavelle, Thermostability of the coating, antigen and immunostimulator in an adjuvanted oral capsule vaccine formulation, International Journal of Pharmaceutics, Volume 534, Issues 1-2, 2017, Pages 60-70, ISSN 0378-5173, DOI: 10.1016/j.ijpharm.2017.10.013.

This Article is brought to you for free and open access by the NanoLab at ARROW@TU Dublin. It has been accepted for inclusion in Articles by an authorized administrator of ARROW@TU Dublin. For more information, please contact arrow.admin@tudublin.ie, aisling.coyne@tudublin.ie,gerard.connolly@tudublin.ie.

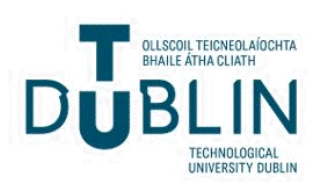




\section{Authors}

Stephanie Longet, Vincenzo Aversa, Daire O'Donnell, Joshua Tobias, Monica Rosa, Jan Holmgren, Ivan Coulter, and Ed Lavelle 
Research Paper

\title{
Thermostability of the coating, antigen and immunostimulator in an adjuvanted oral capsule vaccine formulation
}

\author{
Stephanie Longet ${ }^{\mathrm{a}}$, Vincenzo Aversa ${ }^{\mathrm{b}}$, Daire O’Donnell ${ }^{\mathrm{b}, \mathrm{c}}$, Joshua Tobias ${ }^{\mathrm{d}}$, Monica Rosa ${ }^{\mathrm{b}}$, \\ Jan Holmgren ${ }^{\mathrm{d}}$, Ivan S. Coulter ${ }^{\mathrm{b}}$, Ed C. Lavelle ${ }^{\mathrm{a}, \mathrm{e}, *}$ \\ a Adjuvant Research Group, School of Biochemistry and Immunology, Trinity Biomedical Sciences Institute, Trinity College Dublin, D02 R590, Dublin 2, Ireland \\ b Sigmoid Pharma Limited, Dublin City University, Invent Centre, Dublin, Ireland \\ c FOCAS Research Institute, Dublin Institute of Technology, Kevin St., Dublin 8, Ireland \\ d University of Gothenburg Vaccine Research Institute (GUVAX), Dept. of Microbiology and Immunology, University of Gothenburg, Box 435, 405 30 Gothenburg, Sweden \\ e Centre for Research on Adaptive Nanostructures and Nanodevices (CRANN) \& Advanced Materials Bio-Engineering Research Centre (AMBER), Trinity College Dublin, \\ Dublin 2, Ireland
}

\section{A R T I C L E I N F O}

Chemical compounds studied in this article:

Alpha-Galactosylceramide (KRN 7000)

(PubChem CID: 2826713)

Sorbitol (PubChem CID: 5780)

Kolliphor HS 15 (Solutol ${ }^{\star}$ HS 15) (PubChem

CID: 71311956)

Eudragit L30D 55 and Eudragit L100 55

(Alcogum) (PubChem CID: 107665)

Keywords:

Vaccine

Oral delivery

Adjuvant

Capsule

Stability study

\begin{abstract}
A B S T R A C T
Oral vaccines present an attractive alternative to injectable vaccines for enteric diseases due to ease of delivery and the induction of intestinal immunity at the site of infection. However, susceptibility to gastrointestinal proteolysis, limited transepithelial uptake and a lack of clinically acceptable adjuvants present significant challenges. A further challenge to mass vaccination in developing countries is the very expensive requirement to maintain the cold chain. We recently described the effectiveness of a Single Multiple Pill ${ }^{\circ}$ (SmPill ${ }^{\circ}$ ) adjuvanted capsule approach to enhance the effectiveness of a candidate enterotoxigenic Escherichia coli (ETEC) oral vaccine. Here it was demonstrated that this delivery system maintains the antigenicity of ETEC colonisation factor antigen I (CFA/I) and the immunostimulatory activity of the orally active $\alpha$-Galactosylceramide ( $\alpha$-GalCer) adjuvant after storage of $\mathrm{SmPill}^{\circ}$ minispheres under room temperature and extreme storage conditions for several months. In addition, the internal structure of the cores of SmPill ${ }^{\circ}$ minispheres and antigen release features at intestinal $\mathrm{pH}$ were found to be preserved under all these conditions. However, changes in the surface morphology of SmPill ${ }^{\varpi}$ minispheres leading to the antigen release at gastric $\mathrm{pH}$ were observed after a few weeks of storage under extreme conditions. Those modifications were prevented by the introduction of an Opadry White film coating layer between the core of SmPill ${ }^{\circ}$ minispheres and the enteric coating. Under these conditions, protection against antigen release at gastric $\mathrm{pH}$ was maintained even under high temperature and humidity conditions. These results support the potential of the SmPill ${ }^{\circledR}$ minisphere approach to maintain the stability of an adjuvanted whole cell killed oral vaccine formulation.
\end{abstract}

\section{Introduction}

Enteric infections causing diarrhoeal episodes are a major worldwide health problem leading to high levels of mortality and morbidity, especially in developing countries (Cheng et al., 2005). Even though oral rehydration therapy has helped to reduce the number of deaths, enteric infections still kill approximately 600,000 children under the age of 5 years and result in millions of hospitalizations each year in developing countries (Czerkinsky and Holmgren, 2009; Walker and Clifford, 2015). Moreover these diseases may impact on intestinal absorption, nutrition and child development (Petri et al., 2008). Severe acute diarrhoea can be caused by a number of pathogens including rotaviruses, Vibrio cholerae, Shigella spp., Salmonella spp. and pathogenic strains of Escherichia coli (E. coli) (Girard et al., 2006). One of the most common diarrhoeal diseases detected among children in developing countries and in people travelling to these regions is due to enterotoxigenic Escherichia coli (ETEC) (Qadri et al., 2005). ETEC strains are ingested with contaminated water or food and induce diarrhoea, abdominal cramps, vomiting as well as fever (Qadri et al., 2005). ETEC surface proteins named colonisation factors antigens (CFAs) (pili/

Abbreviations: $\alpha$-GalCer, $\alpha$-Galactosylceramide; BSA, bovine serum albumin; CFA, colonisation factor antigen; Con A, concanavalin A; E. coli, Escherichia coli; DMSO, dimethyl sulfoxide;

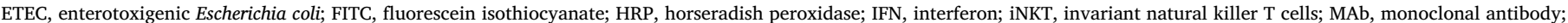
PBS, phosphate buffered saline; RH, relative humidity; SEM, scanning electron microscopy; SmPill" single multiple pill

* Corresponding author at: Adjuvant Research Group, School of Biochemistry and Immunology, Trinity Biomedical Sciences Institute, Trinity College Dublin, D02 R590, Dublin 2, Ireland.

E-mail address: lavellee@tcd.ie (E.C. Lavelle). 
fimbrial or nonfimbrial) such as CFA/I and powerful secreted enterotoxins are key virulence factors (Tobias et al., 2008; Tobias and Svennerholm, 2012; Lundgren et al., 2014). The CFAs bind to glycoprotein or glycolipid receptors on host epithelial cells of the small intestinal mucosa, which leads to bacterial colonisation and multiplication (Jansson et al., 2006). Colonising bacteria induce fluid and electrolyte secretion into the lumen by the production of heat-labile or heat-stable enterotoxin, or both (Qadri et al., 2005). Local secretory antibody responses against CFAs were shown to play a key role in protective immunity both in animal studies and humans (Svennerholm et al., 1988; Ahren and Svennerholm, 1982; Qadri et al., 2007) and consequently CFAs have been the focus for incorporation into ETEC vaccine candidates (Tobias et al., 2008; Tobias and Svennerholm, 2012; Lundgren et al., 2014; Walker et al., 2007).

Oral vaccine delivery is regarded as the optimal means to fight enteric infections as it induces intestinal immunity through the gutassociated mucosal tissues and is also attractive in avoiding the use of needles and enhancing patient compliance. However, oral vaccines have to overcome significant challenges including the low $\mathrm{pH}$ of the stomach, proteolytic enzymes and bile salts, limited uptake across the epithelium and a generally poor immunogenicity of orally delivered antigens (Marasini et al., 2014; Rhee et al., 2012; Davitt and Lavelle, 2015).

In order to overcome these challenges, a number of oral vaccine delivery technologies are currently under pre-clinical and clinical development (Gupta et al., 2007; Wang et al., 2015; Aguirre et al., 2016). Self-emulsifying lipid based systems, composed of oils, surfactants, cosurfactants as well as co-solvents, are widely used (Aguirre et al., 2015). Oil-in-water emulsions formed in aqueous gastrointestinal fluids enhance bioavailability by the formation of small oil droplets which may be lysed by pancreatic lipases, leading to drug release (Kohli et al., 2010). Oil-in-water emulsions may be delivered in solid oral dosage forms such as soft gelatine capsules, pellets, microspheres and minispheres (Aguirre et al., 2015). A novel oral delivery system, Single Multiple Pill ${ }^{\circ}\left(S_{P}\right.$ Pill $\left.^{\circ}\right)$, containing emulsions formulated as minispheres, is able to enhance local, topical drug (e.g. cyclosporine (Keohane et al., 2016), celecoxib (McDonald et al., 2015), calcitonin (Aguirre et al., 2015) or dimethyloxalylglycine (Tambuwala et al., 2015)) efficacy through site-specific release in intestinal regions. This can be achieved through the application of a specific exterior coating to the core of the minispheres. It has been hypothesized that this novel oral delivery system in combination with an efficacious oral adjuvant could be used to deliver oral vaccines and increase antigen immunogenicity by protection from gastric acidity and enhancing sitespecific delivery in the gastrointestinal tract, particularly the jejenum and ileum as these intestinal regions contain gut-associated lymphoid tissues such as Peyer's patches and mucosal immune cells to elicit gut immune responses (Mowat and Agace, 2014). It has been recently demonstrated that the integrated SmPill ${ }^{\circledR}$ system incorporating a recombinant formalin-killed whole cell $E$. coli overexpressing CFA/I and the orally active invariant natural killer T (iNKT) cell activator $\alpha$-Galactosylceramide ( $\alpha$-GalCer) was able to potentiate immune response to this ETEC candidate vaccine (Davitt et al., 2016).

Similarly to pharmaceuticals and biologics, stability tests are essential and mandatory steps in the development of vaccines. However, additional considerations apply to vaccines comprising complex mixtures of active components and in this case, the integration of antigen and adjuvant in the SmPill ${ }^{\circ}$ delivery system. Environmental factors such as temperature, humidity or light might affect SmPill ${ }^{\circ}$ minispheres containing the ETEC vaccine formulation and impact on the efficacy of the integrated system. The goal of this study was to evaluate the effects of temperature and humidity on CFA/I antigenicity, $\alpha$-GalCer immunostimulatory properties, SmPill ${ }^{\circ}$ minisphere structure and bacterial release. The effects of long-term storage at room temperature: $25^{\circ} \mathrm{C}$ / $60 \%$ Relative Humidity (RH) (normal condition), were compared to the effects of more extreme storage conditions such as $30{ }^{\circ} \mathrm{C} / 65 \% \mathrm{RH}$ (intermediate condition) and $40{ }^{\circ} \mathrm{C} / 75 \% \mathrm{RH}$ (accelerated condition). It has been observed that the core of SmPill ${ }^{\circ}$ minispheres fully retained its initial structure and its antigen release properties at intestinal $\mathrm{pH}$ under normal and extreme storage conditions up to 12 months. Importantly, the CFA/I antigenicity and adjuvant $\alpha$-GalCer activity were very well maintained inside the core even when SmPill ${ }^{\circ}$ minispheres were stored under extreme conditions for several months. It was also found that the protection of antigen facilitated by a specific Eudragit coating avoiding its release at gastric $\mathrm{pH}$ was effective at $25{ }^{\circ} \mathrm{C} / 60 \% \mathrm{RH}$. However, the resistance of Eudragit L30D 55 enteric coating to acidic $\mathrm{pH}$ was shown to decrease due to surface modifications at $30{ }^{\circ} \mathrm{C} / 65 \% \mathrm{RH}$ and especially at $40{ }^{\circ} \mathrm{C} / 75 \% \mathrm{RH}$. However, the use of a double-layer coating made of an inner Opadry ${ }^{\circ}$ White film and an outer Eudragit ${ }^{\circ}$ L100 55 film demonstrated an improved resistance of SmPill ${ }^{\circ}$ minispheres at acidic $\mathrm{pH}$ when stored under elevated temperature and humidity.

This study supports the potential of SmPill ${ }^{\oplus}$ minispheres to maintain the stability of the antigen (CFA/I E. coli) and adjuvant ( $\alpha$-GalCer) vaccine components over long-term storage under unrefrigerated conditions.

\section{Materials and methods}

\subsection{Composition and manufacture of SmPill ${ }^{\circledR}$ minispheres}

Three SmPill ${ }^{\circledR}$ minispheres contained $3 \times 10^{8}$ whole-cell killed $E$. coli overexpressing CFA/I with or without $10 \mu \mathrm{g} \alpha$-Galcer (Davitt et al., 2016). Placebo SmPill ${ }^{\circ}$ minispheres containing neither bacteria nor $\alpha$ Galcer were also prepared.

SmPill $^{\circ}$ minispheres were manufactured as previously described (Davitt et al., 2016). Briefly, when included in a formulation, $\alpha$-Galcer (Avanti Polar Lipids Inc., USA) was dissolved in Kolliphor HS 15 (BASF $\mathrm{GmbH}$, Germany) under magnetic stirring. The loading of $\alpha$-Galcer was approximatively $0.1 \%$. Whole-cell formalin killed recombinant $E$. coli C600 strain overexpressing CFA/I (JT-49; generously provided by Prof. Ann-Marie Svennerholm) in a PBS suspension was then added and the resulting dispersed phase mixed until homogeneous. Sorbitol (Roquette Freres, France) was dissolved in water at room temperature, then type A porcine gelatine (Nitta Gelatin NA Inc., USA) was added, the temperature was increased to $60-70{ }^{\circ} \mathrm{C}$ and the mixture stirred until complete dissolution of the components. The aqueous phase and dispersed phase were mixed to achieve homogeneity. The homogeneous dispersion was ejected through a single orifice to form droplets that fell into a cooling oil medium (Miglyol 810N, Cremer Oleo GmbH;Co. KG, Germany) at $8-10{ }^{\circ} \mathrm{C}$. After approximately $30 \mathrm{~min}$, the minispheres were recovered from the cooling oil medium, centrifuged to eliminate excess oil and dried at room temperature. When required, SmPill ${ }^{\circ}$ minispheres were coated using a Vector MFL.01 Fluid Bed System in the bottom spray configuration with an enteric polymer, Eudragit L30D 55 or Eudragit L100 55 (Evonik Industries AG, Germany) that are soluble in intestinal fluid from $\mathrm{pH}$ 5.5. In some cases, Opadry White film $20 \mathrm{~A} 28380$ (Colorcon) was also applied between the core and the enteric polymer to provide a double-layer coating. Minisphere size was measured by light microscopy (BX51 Olympus) and was between 1 and $2 \mathrm{~mm}$.

\subsection{SmPill storage conditions}

Coated, uncoated and placebo SmPill ${ }^{\circ}$ minispheres were stored in open glass vials at $25^{\circ} \mathrm{C} / 60 \% \mathrm{RH}, 30{ }^{\circ} \mathrm{C} / 65 \% \mathrm{RH}$ and $40{ }^{\circ} \mathrm{C} / 75 \% \mathrm{RH}$. The vials were placed in smaller sealed chambers where the RH was controlled using a saturated salt solution and the chambers were placed in incubators.

The storage conditions were chosen according to the ICH guidelines 'Stability Testing of new Drug Substances and Products' (ICH Topic Q 1A (R2), European Medicines Agency, 2003) (2003). 


\subsection{Microscopic analysis of SmPill minisphere structure and antigen localization}

SmPill minispheres were embedded in TissueTek OCT compound (Sakura Finetek) and snap frozen in liquid nitrogen. Sections $(7-10 \mu \mathrm{m})$ were blocked in phosphate buffered saline (PBS)-1\% Bovine serum albumin (BSA) for $30 \mathrm{~min}$ and stained for $1 \mathrm{~h}$ with mouse anti-CFA/I mAb (supplied by Prof. Ann-Mari Svennerholm) diluted 1:25 in PBS-0.1\% BSA followed by fluorescein isothiocyanate (FITC)-conjugated antimouse IgG (eBioscience) diluted 1:50 in PBS-0.1\% BSA for $1 \mathrm{~h}$. The sections were observed using the Leica SP8 gated STED confocal (SBI microscopy facility, Trinity Biomedical Sciences Institute).

\subsection{Bacterial loading and CFA/I antigenicity in SmPill ${ }^{\circ}$ minispheres}

Three SmPill ${ }^{\oplus}$ minispheres were incubated in $100 \mu$ of simulated intestinal fluid $\left(6.8 \mathrm{~g} / 1 \mathrm{NH}_{2} \mathrm{PO}_{4}, 7.7 \% 0.2 \mathrm{~N} \mathrm{NaOH}, 10 \mathrm{~g} / 1\right.$ pancreatin from porcine pancreas (Sigma Aldrich); $\mathrm{pH} 6.8$ ) at $37{ }^{\circ} \mathrm{C}$ with shaking until they fully dissolved. The solutions containing the dissolved SmPill ${ }^{\circ}$ minispheres were serially diluted and analysed by CFA/I-specific dot-blot assay ( $2 \mu \mathrm{l}$ of solution/dilution) using mouse anti-CFA/I $\mathrm{mAb}$, diluted 1:100 in PBS-Tween-0.1\% BSA for $2 \mathrm{~h}$ followed by Horseradish peroxidase (HRP)-conjugated anti-mouse IgG (Southern Biotech) diluted 1:2000 in PBS-Tween-0.1\% BSA for $2 \mathrm{~h}$. Nitrocellulose membranes (Whatman, GE Healthcare) were developed by using the Clarity ECL Western Blot Substrate Kit (Bio-Rad). Densitometric analysis was performed by using the software Image $\mathrm{J}$ and data were plotted as curves. Each point of the curve is the arithmetic mean of signal intensity ( \pm Standard Errors at the Mean) at each specific dilution.

\subsection{Bacterial release from SmPill ${ }^{\curvearrowleft}$ minispheres}

Three SmPill $^{\oplus}$ minispheres were incubated in $100 \mu$ of simulated intestinal fluid or simulated gastric fluid $(2 \mathrm{~g} / 1 \mathrm{NaCl}, 0.7 \%$ concentrate $\mathrm{HCl}, 3.2 \mathrm{~g} / 1$ pepsin derived from porcine stomach mucosa (Sigma Aldrich); $\mathrm{pH} 1.2$ ) at $37^{\circ} \mathrm{C}$ with shaking for $1 \mathrm{~h}$. Bacterial release was analysed by CFA/I-specific dot-blot assay. Every ten minutes, samples $(2 \mu \mathrm{l})$ were collected from SmPill ${ }^{\circ}$ minispheres incubated in simulated intestinal fluid or gastric fluid and subsequently spotted onto the nitrocellulose membrane. The dot-blot assay was performed using mouse anti-CFA/I mAb diluted 1:100 in PBS-Tween-0.1\% BSA for $2 \mathrm{~h}$ followed by HRP-conjugated anti-mouse IgG (Southern Biotech) diluted 1:2000 in PBS-Tween-0.1\% BSA for $2 \mathrm{~h}$. Nitrocellulose membranes (Whatman, GE Healthcare) were developed using the Clarity ECL Western Blot Substrate Kit (Bio-Rad). Densitometric analysis was performed by using the software Image $J$ and data were plotted as curves. Each point of the curve is the arithmetic mean of signal intensity ( \pm Standard Errors of the Mean) at each specific time-point of the dot-blot assays.

\subsection{Scanning electron microscopy analysis of coated SmPill ${ }^{\oplus}$ minispheres}

$\mathrm{SmPill}^{\oplus}$ minispheres were cut, gold/palladium coated for $60 \mathrm{~s}$ and observed using a Zeiss Ultra Field Emission Scanning Electron Microscope (CRANN Advanced Microscopy Laboratory, TCD; Vendor: Zeiss) or a Hitachi SU 6600 Field Emission Scanning Electron Microscope (FOCAS Research Institute, Dublin Institute of Technology; Vendor: Hitachi). A secondary electron detector was used and samples were imaged at $1.5-5 \mathrm{Kv}$. The thickness of enteric coating of SmPill ${ }^{\circ}$ minispheres was measured by using the software Image $\mathrm{J}$.

\subsection{Stimulation of murine splenocytes with dissolved SmPill minispheres and measurement of IFN $\gamma$ release}

Wild type male C57BL/6 mice were obtained from Charles River Laboratories, Inc., and were euthanized at 12-16 weeks of age. Animals were maintained according to the regulations of the EU and the Irish Department of Health and all procedures performed were conducted under animal licence number B100/3321 and were approved by the Trinity College Dublin Animal Research Ethics Committee (Ethical Approval Number 091210).

Mice were sacrificed by cervical dislocation before removal of spleens. Single cell suspensions were prepared by disrupting tissue through $40 \mu \mathrm{m}$ nylon cell strainers (BD Falcon) with RPMI 1640 medium (Gibco, Life Technologies) supplemented with 1\% Penicillin/ Streptomycin 100x (Gibco Life Technologies), 1\% L-glutamine $200 \mathrm{mM}$ (Gibco Life Technologies) and 10\% heat-inactivated and filtered Fetal Bovine Serum (Biosera). For red blood cell lysis, cell pellets were resuspended in $1 \mathrm{ml} 0.88 \%$ ammonium chloride solution (Sigma) for $2 \mathrm{~min}$ and washed in supplemented RPMI medium. After centrifugation, cells were plated at $5 \times 10^{5}$ /well in $100 \mu$ of complete RPMI medium: RPMI 1640 medium supplemented with $10 \%$ heat-inactivated and filtered Fetal Bovine Serum (Biosera), 1\% sodium pyruvate $100 \mathrm{mM} 100 \mathrm{x}$ (Gibco Life Technologies), 1\% Non-essential amino acids 100x (Gibco Life Technologies), 1\% L-glutamine $200 \mathrm{mM}$ (Gibco Life Technologies), 0.1\% Penicillin/Streptomycin 100x (Gibco Life Technologies), $0.1 \%$ Mercaptoethanol $55 \mathrm{mM}$ (Gibco Life Technologies), 0.4\% MEM vitamins (Gibco Life Technologies).

Splenocytes were stimulated for $72 \mathrm{~h}$ at $37{ }^{\circ} \mathrm{C} / 5 \% \mathrm{CO}_{2}$ with the following stimuli in $100 \mu \mathrm{l}$ of complete RPMI medium: Concanavalin A (Con A) ( $4 \mu \mathrm{g} / \mathrm{ml}$, Sigma), $\alpha$-GalCer in solution ( $10 \mathrm{ng} / \mathrm{ml})$, Dimethyl sulfoxide (DMSO), the vehicle agent to dissolve $\alpha$-GalCer in solution (1/ 1000, Sigma) or the dissolved SmPill ${ }^{\oplus}$ minispheres. SmPill ${ }^{\varpi}$ minispheres were dissolved in simulated intestinal fluid as described above. These solutions were diluted $1 / 8000$ in order to be in the same range as the $\alpha$ GalCer positive control and in order to dilute the simulated intestinal fluid sufficiently to avoid interference with the assays. IFN $\gamma$ release in supernatants was measured $72 \mathrm{~h}$ post-stimulation using the Mouse IFN $\gamma$ DuoSet ELISA Kit (R \& D systems).

\subsection{Statistical analysis}

Statistical analysis was performed using Prism 6 software (GraphPad Software). For the study of CFA/I antigenicity in SmPill ${ }^{\circ}$ minispheres (2.4), the unpaired nonparametric Kruskal-Wallis test (nonparametric oneway ANOVA) followed by a Dunn's multiple comparisons test were used to calculate the differences between the slopes on the linear section of the curves performed from densitometric analyses of dot-blot assays. Differences were considered as significant when $\mathrm{p}<0.05$. In order to assess the linear relationship between the dilution and signal intensity values included in the statistical analysis, the coefficient of determination $\left(\mathrm{r}^{2}\right)$ was calculated before running the above mentioned tests. All $\mathrm{r}^{2}$ are equal to 0.98-0.99.

\section{Results}

3.1. Characterization of coated and uncoated SmPill minispheres used for the thermostability study

SmPill ${ }^{\circledR}$ minispheres are beads comprising a core and a coating surrounding the whole core (Fig. 1a). As previously described (Davitt et al., 2016), the core is constituted of an emulsion containing droplets in liquid phase dispersed in a gelatin matrix. The droplets contain the $E$. coli overexpressing the antigen CFA/I (CFA/I E. coli) and the adjuvant $\alpha$-GalCer. The Eudragit L30D 55 coating is an enteric polymer soluble in intestinal fluid from $\mathrm{pH}$ 5.5.

In order to evaluate the degree of intra- and inter-batch variability observed at the level of core and coating properties of SmPill ${ }^{\varpi}$ minispheres, uncoated and Eudragit L30D 55 coated CFA/I E. coli and $\alpha$ GalCer-containing SmPill ${ }^{\circ}$ minisphere batches used for this stability study were characterized and compared to two other batches. The size of coated and uncoated SmPill ${ }^{\oplus}$ minispheres was measured by light 
A.

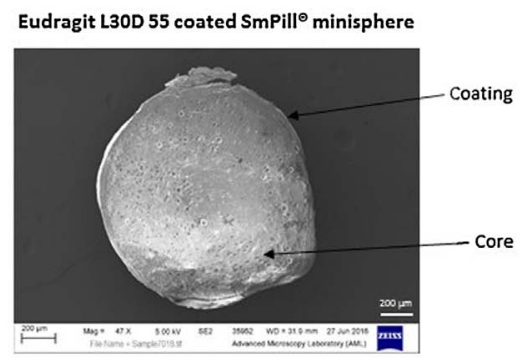

c.

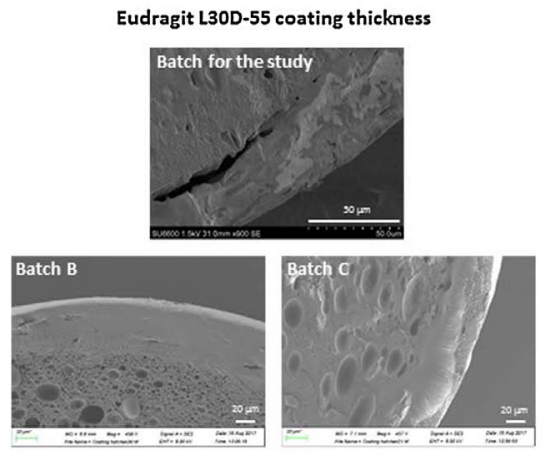

B.

\begin{tabular}{|c|c|c|c|}
\hline \multicolumn{2}{|c|}{$\begin{array}{l}\text { Size of coated and uncoated SmPill } \\
\text { minispheres used for the study }\end{array}$} & \multicolumn{2}{|c|}{ Size of SmPill ${ }^{\ominus}$ minispheres of other batches } \\
\hline \multicolumn{2}{|c|}{ Size (average $\mathrm{mm} \pm \mathrm{SD}$ ) } & \multicolumn{2}{|c|}{ Size (average $\mathrm{mm} \pm \mathrm{SD}$ ) } \\
\hline $\begin{array}{l}\text { Batch of Eudragit } L 300 \\
55 \text { coated SmPill }\end{array}$ & $1.18 \pm 0.03$ & $\begin{array}{l}\text { Batch B of Eudragit } \\
\text { L30D } 55 \text { coated SmPill" }\end{array}$ & $1.32 \pm 0.06$ \\
\hline $\begin{array}{l}\text { Batch of uncoated } \\
\text { SmPill }\end{array}$ & $1.22 \pm 0.12$ & $\begin{array}{l}\text { Batch C of Eudragit } \\
\text { L30D } 55 \text { coated SmPill }\end{array}$ & $1.45 \pm 0.08$ \\
\hline
\end{tabular}

D.

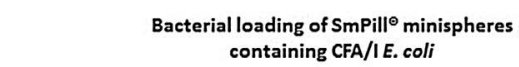

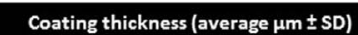

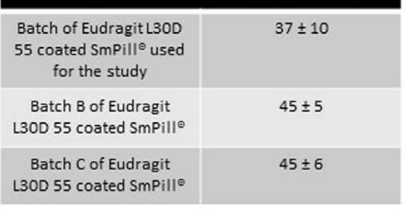

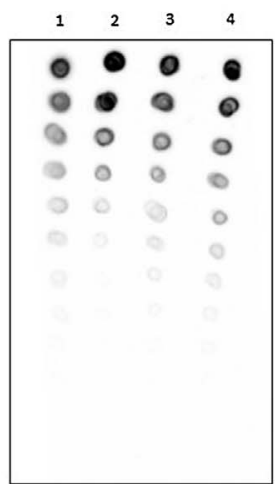

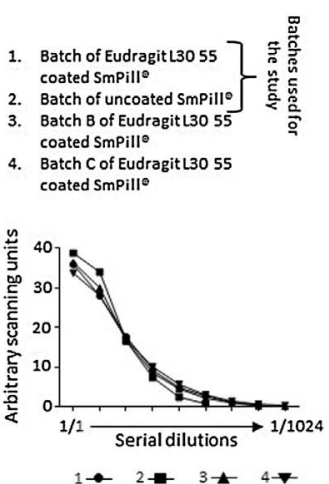

Fig. 1. Characterization of Eudragit L30D 55 coated and uncoated SmPill ${ }^{\circ}$ minispheres used for stability studies.

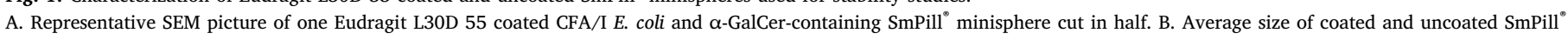

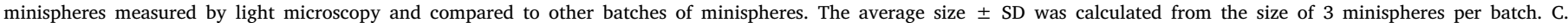

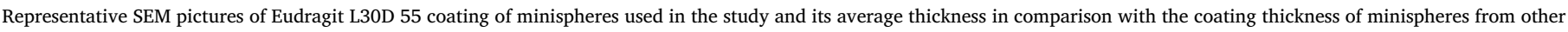

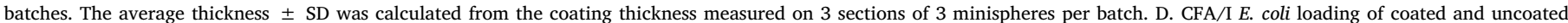

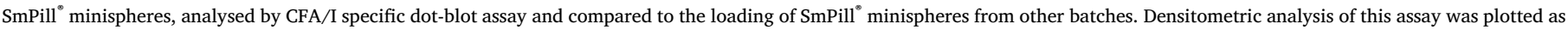
a curve where each point is the percentage of signal at each specific dilution.

microscopy. The average sizes of coated and uncoated minispheres were $1.18 \pm 0.03 \mathrm{~mm}$ and $1.22 \pm 0.12 \mathrm{~mm}$, respectively. This size is close to the size of minispheres into two separately produced batches which measured $1.32 \pm 0.06 \mathrm{~mm}$ and $1.45 \pm 0.08 \mathrm{~mm}$ respectively (Fig. 1b). In addition, the coating thickness of SmPill ${ }^{\circ}$ minispheres was analysed by SEM. The average thickness of the Eudragit L30D 55 coating of SmPill ${ }^{\circ}$ minisphere used for the study was $37 \pm 10 \mu \mathrm{m}$ (Fig. 1c). In comparison, the average coating thicknesses of SmPill ${ }^{\circ}$ minispheres from other batches were $45 \pm 5 \mu \mathrm{m}$ and $45 \pm 6 \mu \mathrm{m}$ (Fig. 1c). However, even though a certain degree of size and coating thickness variability was observed between SmPill ${ }^{\circ}$ batches, the bacterial loading of SmPill ${ }^{\circ}$ minispheres studied by a CFA/I-specific dotblot assay was similar between the batches. Indeed, the densitometric analysis did not reveal significant differences in signal intensity across the serial dilutions (Fig. 1d).

These data provided valuable measures of key SmPill ${ }^{\circ}$ minisphere features, including coating thickness and CFA- 1 antigenicity, which can be evaluated after exposure of coated CFA/I E. coli and $\alpha$-GalCer SmPill ${ }^{\oplus}$ minispheres to elevated temperature and humidity for several months.

\subsection{The internal structure of the SmPill minisphere core is maintained after long term storage at elevated temperatures}

In order to determine the effects of sustained exposure to elevated temperature and humidity on the properties of SmPill ${ }^{\oplus}$ minispheres containing CFA/I E. coli (Tobias and Svennerholm, 2012) and $\alpha$-GalCer, Eudragit ${ }^{\circ}$ L30D 55 coated and uncoated SmPill ${ }^{\circ}$ minispheres were exposed to $25^{\circ} \mathrm{C} / 60 \% \mathrm{RH}$ (normal storage condition) and $30{ }^{\circ} \mathrm{C} / 65 \% \mathrm{RH}$ (intermediate storage condition) for up to 12 months as well as to $40{ }^{\circ} \mathrm{C} / 75 \% \mathrm{RH}$ (accelerated storage condition) for up to 6 months as described in the ICH guideline recommendations ('Stability Testing of New Drug Substances and Products' (ICH Topic Q 1A (R2), European
Medicines Agency, 2003)

To observe the internal structure of the SmPill ${ }^{\circ}$ minisphere core, sections of minispheres were stained for CFA/I $E$. coli antigen and observed under a confocal microscope after 3, 6 and 12 months of storage. A section of SmPill ${ }^{\circ}$ minispheres processed at time-point zero and another one from a placebo minisphere without CFA/I E. coli bacteria, were stained and shown as positive and negative controls, respectively.

As previously described (Davitt et al., 2016), droplets of diverse size heterogeneously distributed inside SmPill ${ }^{\circ}$ minisphere cross-sections could be clearly visualized (Fig. 2). The fluorescence microscopy images of SmPill minisphere sections showed that aggregates of killed bacteria were inside or at the surface of the droplets rather than in the gelatin matrix. After 12 months under room temperature and under intermediate storage conditions as well as after 6 months under accelerated storage conditions, the droplets were preserved and the bacteria were still mostly localised inside the droplets similarly to the positive control (Fig. 2). Interestingly, coated and uncoated minispheres exhibited a similar maintenance of the initial internal structure (Suppl. Fig. A.1).

It can be concluded that exposure to elevated temperature and humidity does not modify the internal structure of the SmPill ${ }^{\circ}$ minisphere core and the localisation of formalin-killed CFA/I E. coli.

\subsection{The antigenicity of CFA/I expressed on E. coli within SmPill minispheres is preserved after long term storage at elevated temperatures}

The integrity of vaccine antigens in complex formulations must be maintained under appropriate storage conditions.

In order to analyse the maintenance of CFA/I antigenicity inside the minispheres, Eudragit ${ }^{\circ}$ L30D 55 coated and uncoated SmPill ${ }^{\circ}$ minispheres containing CFA/I $E$. coli and $\alpha$-GalCer were exposed to $25^{\circ} \mathrm{C} /$ $60 \% \mathrm{RH}, 30{ }^{\circ} \mathrm{C} / 65 \% \mathrm{RH}$ and $40{ }^{\circ} \mathrm{C} / 75 \% \mathrm{RH}$ conditions. The minispheres were dissolved in simulated intestinal fluid and CFA/I-specific 


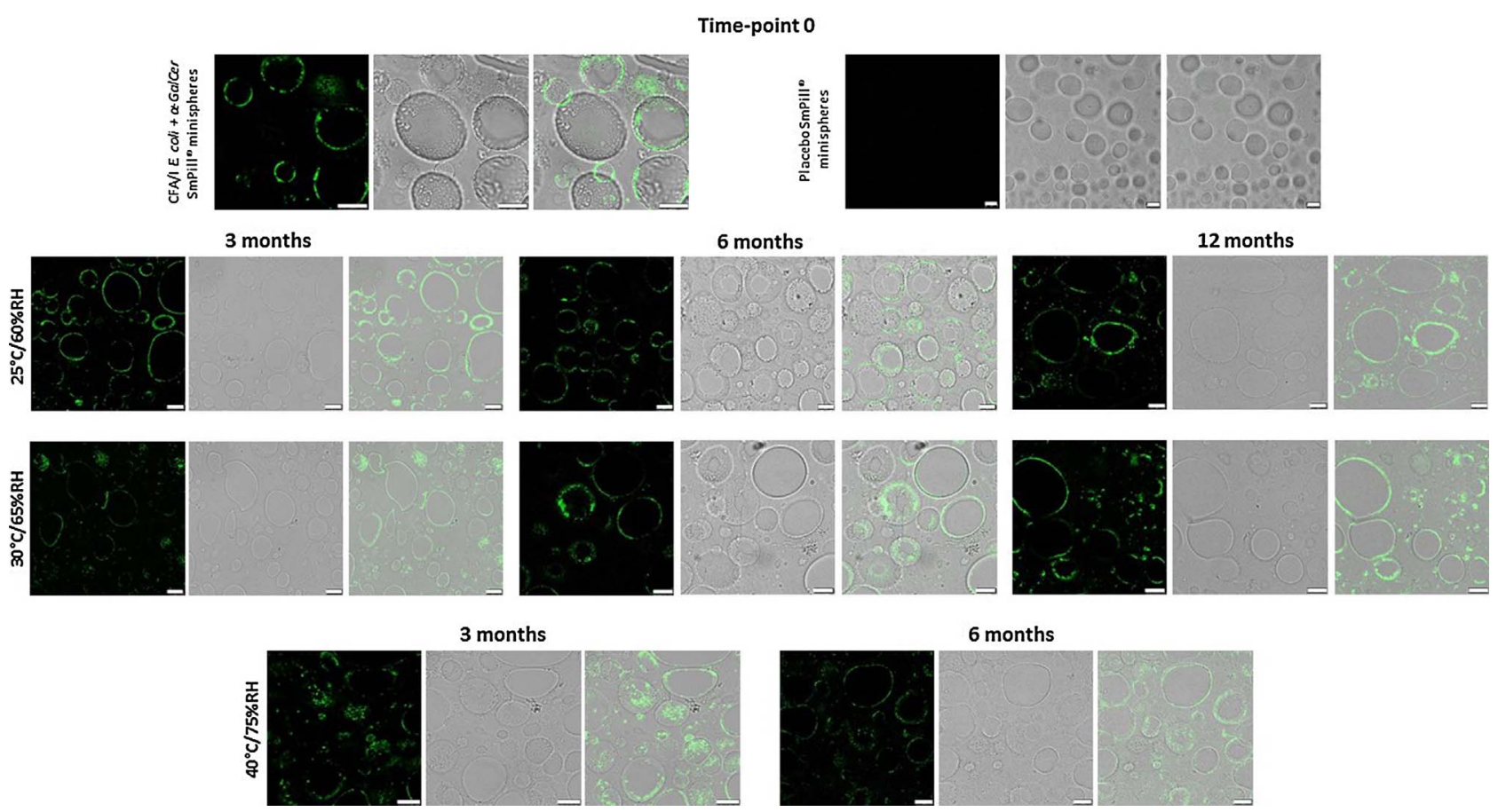

Fig. 2. Internal structure of coated SmPill ${ }^{\circ}$ minisphere core and antigen localization after storage under various temperature and humidity conditions.

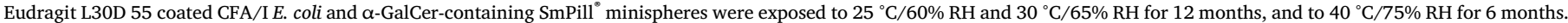

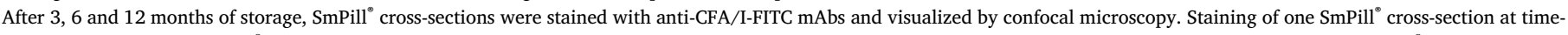

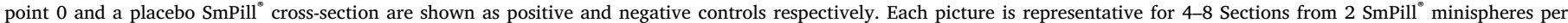
condition. Scale: $25 \mu \mathrm{m}$.

dot-blot assays were performed after 1, 3, 5, 6 and 12 months of storage. The same experiment was also performed at time-point zero and with placebo SmPill ${ }^{\circ}$ minispheres as positive and negative controls respectively.

The assays reveal a remarkable maintenance of CFA/I antigenicity in coated (Fig. 3) and uncoated (Suppl. Fig. A.2) SmPill ${ }^{\circ}$ minispheres at $25{ }^{\circ} \mathrm{C} / 60 \% \mathrm{RH}$, even after exposure at $30{ }^{\circ} \mathrm{C} / 65 \% \mathrm{RH}$ for up to 12 months and at $40{ }^{\circ} \mathrm{C} / 75 \% \mathrm{RH}$ for up to 6 months. Densitometric analyses of dot-blot assays show that no significant differences in signal intensity across the serial dilutions were observed between SmPill ${ }^{\circ}$ minispheres stored under various temperature conditions as well as between coated and uncoated SmPill ${ }^{\circ}$ minispheres (Fig. 3 and Suppl. Fig. A.2).

These data highlight the maintenance of CFA/I antigenicity within SmPill ${ }^{\circ}$ minispheres on long term storage at room and elevated temperatures.

\subsection{The immunostimulatory potential of the adjuvant $\alpha$-GalCer is maintained in SmPill minispheres exposed to high temperature}

In addition to CFA/I antigenicity, maintenance of the adjuvanticity of the iNKT cell-activating glycolipid, $\alpha$-GalCer in the vaccine formulation, is a second crucial point to assess formulation stability. It is known that stimulation by $\alpha$-GalCer induces the production of IFN $\gamma$ by murine splenocytes (Cerundolo et al., 2010; Ando et al., 2013). In order to determine the maintenance of immunostimulatory activity of the adjuvant inside the minispheres, splenocytes were stimulated with dissolved Eudragit ${ }^{\circ}$ L30D 55 coated CFA/I E. coli and $\alpha$-GalCer-containing SmPill minispheres exposed to $25^{\circ} \mathrm{C} / 60 \% \mathrm{RH}, 30{ }^{\circ} \mathrm{C} / 65 \% \mathrm{RH}$ and $40{ }^{\circ} \mathrm{C} / 75 \% \mathrm{RH}$ for 1 or 5 months. Seventy-two hours post-stimulation, IFN $\gamma$ release was measured in supernatants. Stimulation with $\alpha$ GalCer in solution as well as dissolved SmPill containing CFA/I E. coli and $\alpha$-GalCer kept at $4{ }^{\circ} \mathrm{C}$ were shown as positive controls whereas stimulation with placebo SmPill ${ }^{\circ}$ minispheres and SmPill ${ }^{\circ}$ minispheres containing only CFA/I E. coli were shown as negative controls.
Stimulation with dissolved SmPill ${ }^{\circledR}$ minispheres containing CFA/I E. coli and $\alpha$-GalCer that were previously exposed to room temperature or to high temperature and humidity levels demonstrated that the capacity of the incorporated $\alpha$-GalCer to drive IFN $\gamma$ production was comparable to positive controls for up to 5 months (Fig. 4a). There was negligible release of IFN $\gamma$ by splenocytes exposed to dissolved SmPill ${ }^{\circ}$ minispheres containing only CFA/I E. coli or placebo SmPill ${ }^{\circ}$ minispheres (Fig. 4b) indicating that the interferon gamma response was principally driven by the adjuvant.

\subsection{Long term storage at room temperature moderately impacts on the external appearance of SmPill minispheres}

It was hypothesized that the external appearance of SmPill ${ }^{\circ}$ minispheres would provide an indication of modifications to the delivery system through an effect on the enteric coating; therefore, Eudragit ${ }^{\circ}$ L30D 55 coated SmPill minispheres containing CFA/I E. coli and $\alpha$ GalCer were exposed to $25{ }^{\circ} \mathrm{C} / 60 \% \mathrm{RH}, 30{ }^{\circ} \mathrm{C} / 65 \% \mathrm{RH}$ and observed after 3, 6 and 12 months or exposed to $40{ }^{\circ} \mathrm{C} / 75 \% \mathrm{RH}$ and observed after 3 and 6 months (Suppl. Table A.1a). In comparison, the external appearance of uncoated minispheres was also analysed to distinguish the direct effects of temperature and humidity on the core of SmPill ${ }^{\circ}$ minispheres (Suppl. Table A.1b). The selected criteria were colour, shape and external structure of SmPill ${ }^{\circ}$ minispheres. At the beginning of the study, the colour of the coated SmPill ${ }^{\circ}$ was white and opaque. At $25{ }^{\circ} \mathrm{C} / 60 \% \mathrm{RH}, \mathrm{SmPill}{ }^{\circ}$ minispheres were round and white even after 12 months although they became slightly soft and sticky. Under intermediate and accelerated storage conditions, SmPill ${ }^{\circ}$ minispheres became more transparent and turned yellow after 3 months. A stickiness could be also observed under intermediate storage conditions and especially under accelerated storage conditions (Suppl. Table A.1a). However, the average size of SmPill ${ }^{\circ}$ minispheres was unchanged under these conditions (time-point 0: $1.18 \pm 0.03 \mathrm{~mm} ; 5$ months at $25^{\circ} \mathrm{C}$ / $60 \%$ RH: $1.17 \pm 0.13 \mathrm{~mm} ; 30^{\circ} \mathrm{C} / 65 \% \mathrm{RH}: 1.25 \pm 0.04 \mathrm{~mm}$ and at $40{ }^{\circ} \mathrm{C} / 75 \%$ RH: $1.23 \pm 0.06 \mathrm{~mm}$ ). In comparison, uncoated SmPill ${ }^{\circ}$ 
A.
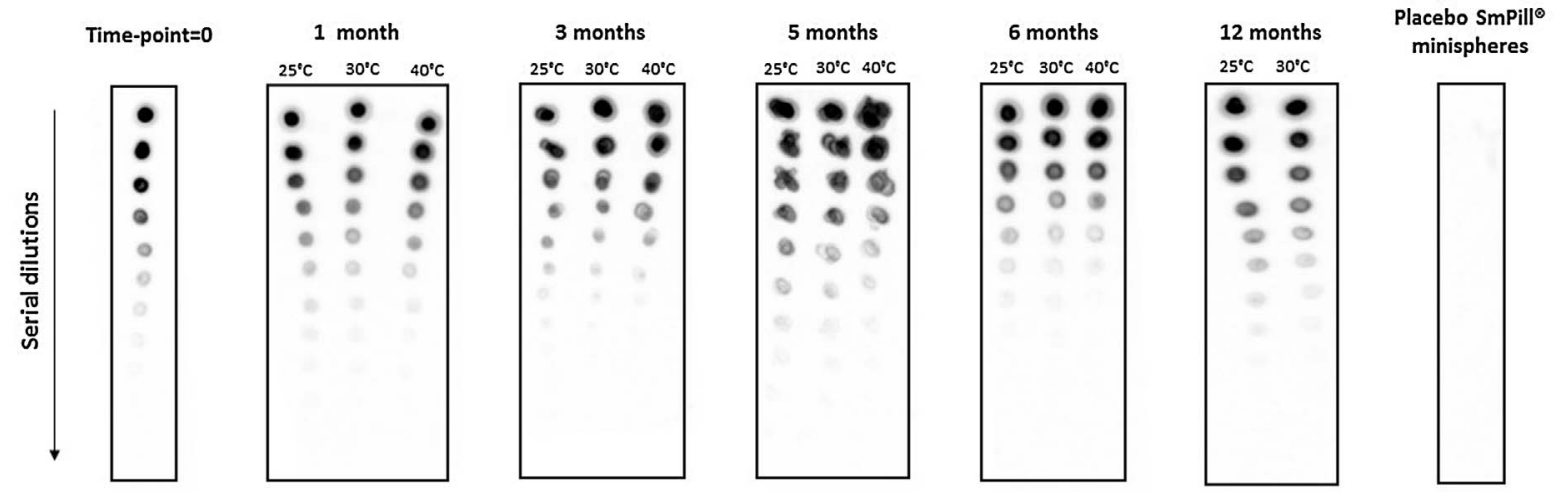

B.
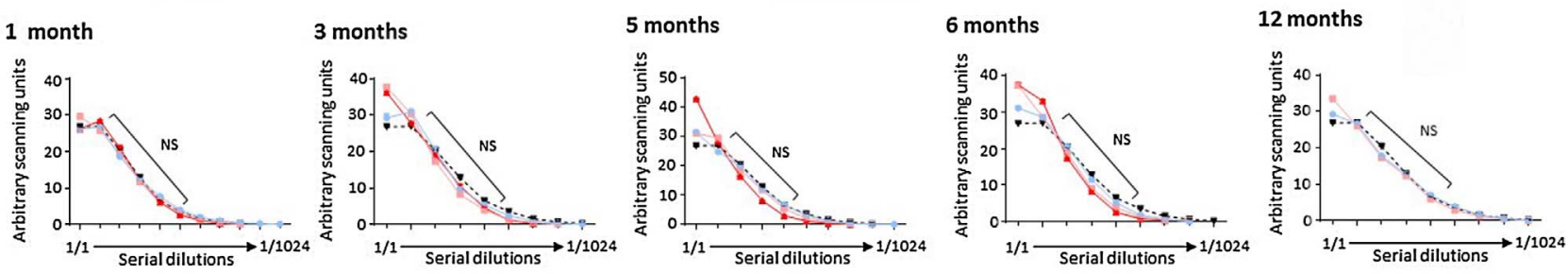

$-25^{\circ} \mathrm{C}-30^{\circ} \mathrm{C} \rightarrow 40^{\circ} \mathrm{C}-7 \cdot$ Time-point 0

Fig. 3. Analysis of CFA/I antigenicity in coated SmPill ${ }^{\circ}$ minispheres stored under various temperature and humidity conditions.

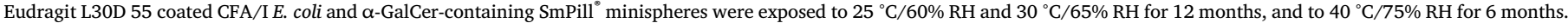

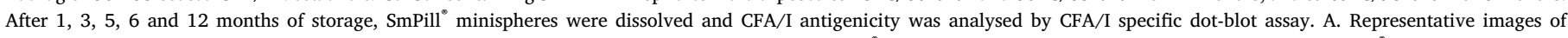

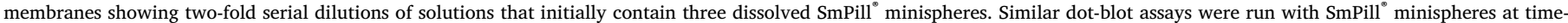

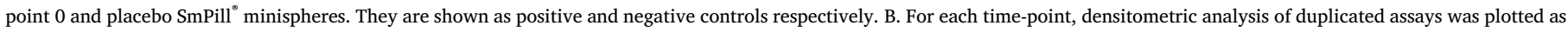

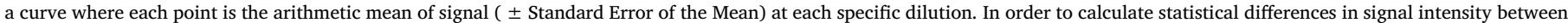
the conditions, a Dunn's multiple comparisons test in one way ANOVA was carried out on the linear sections of the slopes of the curves. NS = non-significant.

minispheres started to turn yellow and became soft after 3 months under all conditions but more markedly after storage at $30{ }^{\circ} \mathrm{C} / 65 \% \mathrm{RH}$ and $40{ }^{\circ} \mathrm{C} / 75 \% \mathrm{RH}$. However, deformation was only observed under accelerated conditions (Suppl. Table A.1b).

The differences in deformation and stickiness were more marked with coated SmPill ${ }^{\circ}$ minispheres compared to uncoated SmPill ${ }^{\circ}$ minispheres suggesting a principal impact of high temperature and humidity levels on the SmPill ${ }^{\circ}$ coating. To examine the enteric coating appearance, Eudragit ${ }^{\circ}$ L30D 55 coated SmPill ${ }^{\circ}$ were observed after exposure to $25{ }^{\circ} \mathrm{C} / 60 \% \mathrm{RH}$ and $30{ }^{\circ} \mathrm{C} / 65 \% \mathrm{RH}$ for 3,6 and 12 months and $40{ }^{\circ} \mathrm{C} /$

A.

CFAll E. coli $+\alpha$-GalCer SmPill ${ }^{\oplus i}$ minispheres

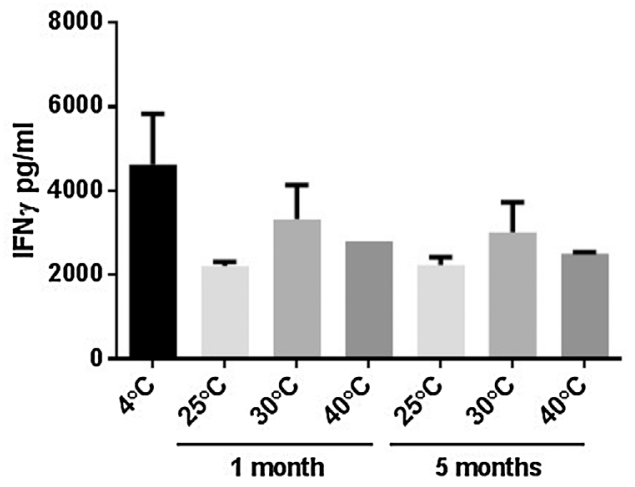

75\% RH for 3 and 6 months. Sectioned minispheres were gold/palladium coated and the enteric coating visualized by SEM. The distribution of the coating was relatively consistent around the minispheres that were exposed to room temperature for 12 months (Fig. 5). The average thickness of the coating only slightly increased over time (time-point 0 : $37 \pm 10 \mu \mathrm{m} ; 12$ months at $25{ }^{\circ} \mathrm{C} / 60 \%$ RH: $58 \pm 10 \mu \mathrm{m}$ ) (Fig. 1; Suppl. Table A.2). However, when SmPill ${ }^{\circ}$ minispheres were stored under intermediate or accelerated storage conditions, significant deformation and changes in the distribution of the coating around the minispheres was visible after 3 months but was strongly intensified after 12 months

B.

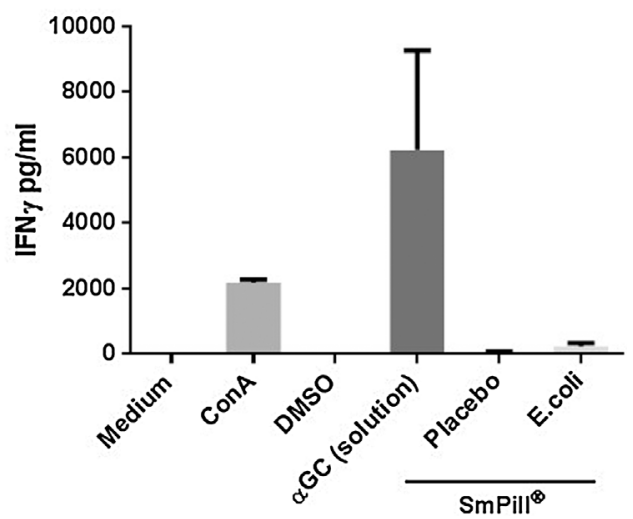

Fig. 4. IFN $\gamma$ release after stimulation of murine splenocytes with $\mathrm{SmPill}^{\circ}$ minispheres exposed to various temperature and humidity conditions.

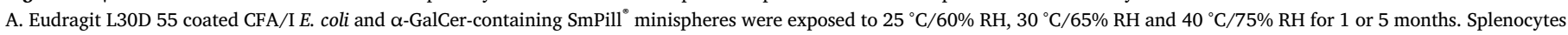

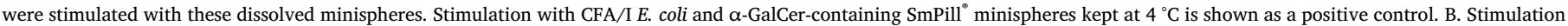

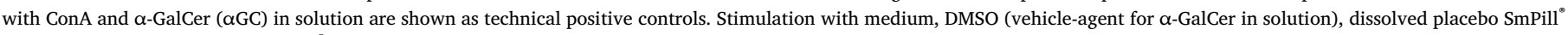
minispheres and CFA/I E. coli SmPill ${ }^{\circ}$ minispheres are shown as negative controls. Representative duplicate experiment. 


\section{Eudragit L30D 55 coated SmPill ${ }^{\circledast}$ minispheres}

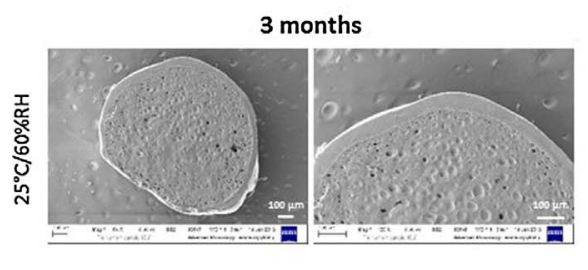

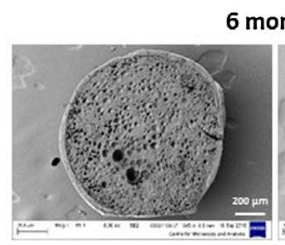

6 months

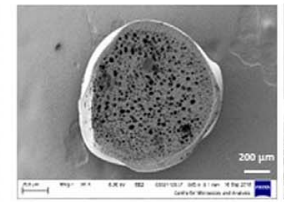

${ }^{2000 m}$

3 months

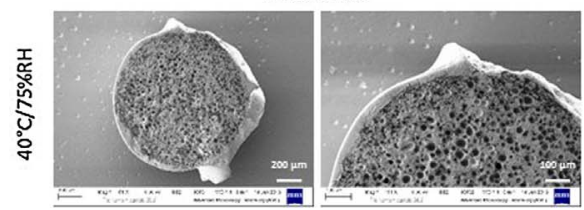

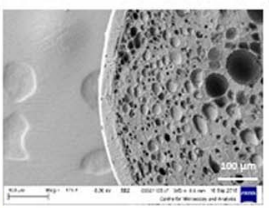
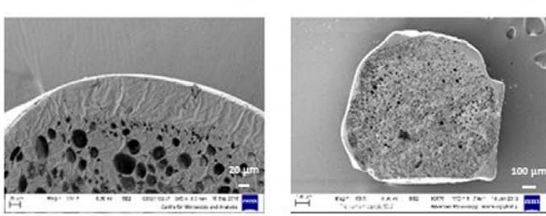

12 months

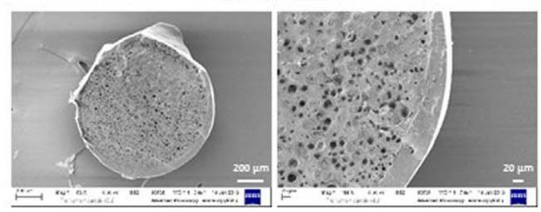

6 months

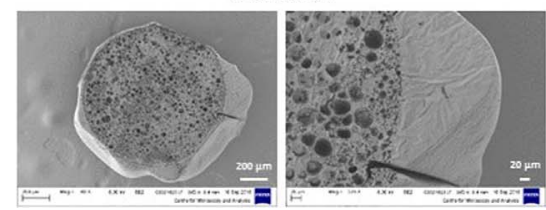

Fig. 5. Visualization of the enteric coating of SmPill ${ }^{\circ}$ minispheres after exposure to various temperature and humidity conditions.

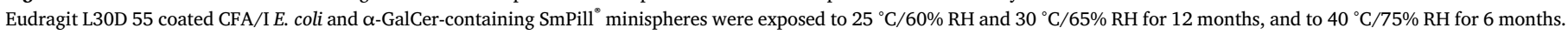

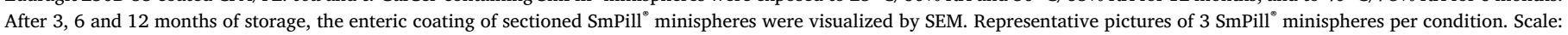
20-200 $\mu \mathrm{m}$.

at $30{ }^{\circ} \mathrm{C} / 65 \% \mathrm{RH}$ and after 6 months at $40{ }^{\circ} \mathrm{C} / 75 \%$ RH (Fig. 5). Under these conditions, the average thickness of coating was significantly increased compared to the thickness at time-point 0 (12 months at $30{ }^{\circ} \mathrm{C} / 65 \%$ RH: $\quad 66 \pm 32 \mu \mathrm{m} ; \quad 6$ months at $40{ }^{\circ} \mathrm{C} / 75 \%$ RH: $100 \pm 52 \mu \mathrm{m}$ ) (Suppl. Table A.2). In addition, the modifications in coating distribution enhanced the thickness variability on each minisphere and between the minispheres (Suppl. Table A.2).

These results illustrate that only moderate modifications are observed on the external appearance and enteric coating of SmPill ${ }^{\circ}$ minispheres stored at room temperature for up to 12 months. In comparison, SmPill ${ }^{\circ}$ minispheres stored under intermediate and accelerated storage conditions showed a change in colour, shape and external structure that could impact on the quality of the enteric coating and would suggest the need for formulation optimization.

3.6. The antigen release characteristics of SmPill ${ }^{\circ}$ minispheres at intestinal $\mathrm{pH}$ are maintained on storage at elevated temperature and humidity for up to 6 months

It was previously demonstrated that SmPill ${ }^{\circ}$ technology prevented antigen release at gastric $\mathrm{pH}$ but facilitated controlled antigen release under conditions found in the distal small intestine due to the application of a specific enteric coating film (Davitt et al., 2016).

In order to examine if these bacterial release characteristics were preserved over time, Eudragit ${ }^{\circ}$ L30D 55 coated CFA/I E. coli and $\alpha$ GalCer-containing SmPill minispheres stored at $25^{\circ} \mathrm{C} / 60 \% \mathrm{RH}$ and $30{ }^{\circ} \mathrm{C} / 65 \%$ RH for $1,3,6$ and 12 months as well as $40{ }^{\circ} \mathrm{C} / 75 \% \mathrm{RH}$ for 1 , 3 and 6 months were exposed to simulated intestinal fluid (pH 6.8 with pancreatin). The release of bacteria was analysed every ten minutes by CFA/I-specific dot-blot assay until full dissolution of minispheres (ca. $60 \mathrm{~min}$ ). Densitometric analyses of the dot-blot assays revealed minimal differences in the kinetics of bacterial release between the different storage conditions at each time-point (Fig. 6).

The application of an enteric coating to SmPill facilitates site-specific release in the small intestine and minimizes degradation under acidic conditions. As recently demonstrated (Davitt et al., 2016), no bacterial release was found when SmPill ${ }^{\circ}$ minispheres were incubated in simulated gastric fluid. In order to determine whether temperature and humidity conditions may impact on the ability of the enteric coating to remain intact in an acidic (gastric) environment, Eudragit ${ }^{\circ}$ L30D 55 coated CFA/I $E$. coli and $\alpha$-GalCer-containing SmPill ${ }^{\circ}$ exposed to $25{ }^{\circ} \mathrm{C} / 60 \% \mathrm{RH}, 30{ }^{\circ} \mathrm{C} / 65 \% \mathrm{RH}$ and $40{ }^{\circ} \mathrm{C} / 75 \% \mathrm{RH}$ for 1,3 and 5 months were incubated in simulated gastric fluid ( $\mathrm{pH} 1.2$, with pepsin). The release of bacteria was analysed by CFA/I-specific dot-blot assay for $60 \mathrm{~min}$. The enteric coating (Eudragit ${ }^{\circ}$ L30D 55) of SmPill ${ }^{\circ}$ minispheres exposed to $25^{\circ} \mathrm{C} / 60 \% \mathrm{RH}$ prevented antigen release at low $\mathrm{pH}$ following storage for 5 months. However, following incubation at more extreme temperature and humidity conditions, densitometric analysis of dot-blot assays revealed a marked loss of resistance of the enteric coating to low $\mathrm{pH}$ solution, particularly from 1 month at $40{ }^{\circ} \mathrm{C} / 75 \% \mathrm{RH}$ (Fig. 7a).

To address this challenge, we examined the efficacy of the Eudragit ${ }^{\circ}$ L100 55 coating which also resists degradation at a pH lower than 5.5. Moreover, we examined whether the addition of an Opadry White protective film on the core was beneficial to improve the coating resistance of Eudragit ${ }^{\circ}$ L100 55. SmPill ${ }^{\circ}$ coated with Eudragit ${ }^{\circ}$ L100 55 alone did not show an improved resistance over those coated with Eudragit ${ }^{\circledast}$ L30D 55 exposed to similar conditions for one month (data not shown). However, the addition of an Opadry White film between the core and the exterior enteric coating conferred an improved resistance. While antigen release was comparable between Eudragit ${ }^{\circ}$ L30D 55 coated SmPill ${ }^{\circ}$ and Eudragit ${ }^{\circ}$ L100 55 + Opadry ${ }^{\circ}$ White coated SmPill $^{\circ}$ in simulated intestinal fluid (Fig. 6; Suppl. Fig. A.3), antigen release was minimal from SmPill ${ }^{\circledR}$ with the double-layer Eudragit ${ }^{\circ}$ L100 $55+$ Opadry ${ }^{\circledR}$ White coating at acidic $\mathrm{pH}$ even when these minispheres were stored at $40{ }^{\circ} \mathrm{C} / 75 \% \mathrm{RH}$ for one month (Fig. $7 \mathrm{~b}$ ). The presence of the double-layer coating was confirmed by microscopy. Sectioned Eudragit L100 55 + Opadry ${ }^{\circ}$ White coated SmPill ${ }^{\circ}$ compared to sectioned Eudragit ${ }^{\circ}$ L30D 55 coated SmPill ${ }^{\circ}$ were gold/palladium coated and visualized by SEM (Fig. 8). The thickness of this double-layer coating was $44 \pm 12 \mu \mathrm{m}$. Finally, similarly to Eudragit L30 55 coated SmPill $^{\circ}$ minsipheres, CFA/I antigenicity and $\alpha$-Galcer immunostimulatory properties were maintained in Eudragit L100 $55+$ Opadry ${ }^{\circ}$ White SmPill ${ }^{\circ}$ minispheres even after long term storage at $40{ }^{\circ} \mathrm{C} / 75 \% \mathrm{RH}$ (Suppl. Fig. A.4).

These data show the flexibility of the SmPill ${ }^{\oplus}$ technology in allowing replacement of specific components to enhance antigen stability and release characteristics at elevated temperature and humidity. 


\section{Eudragit L30D 55 coated SmPill ${ }^{\odot}$ minispheres} in simulated intestinal fluid

A.
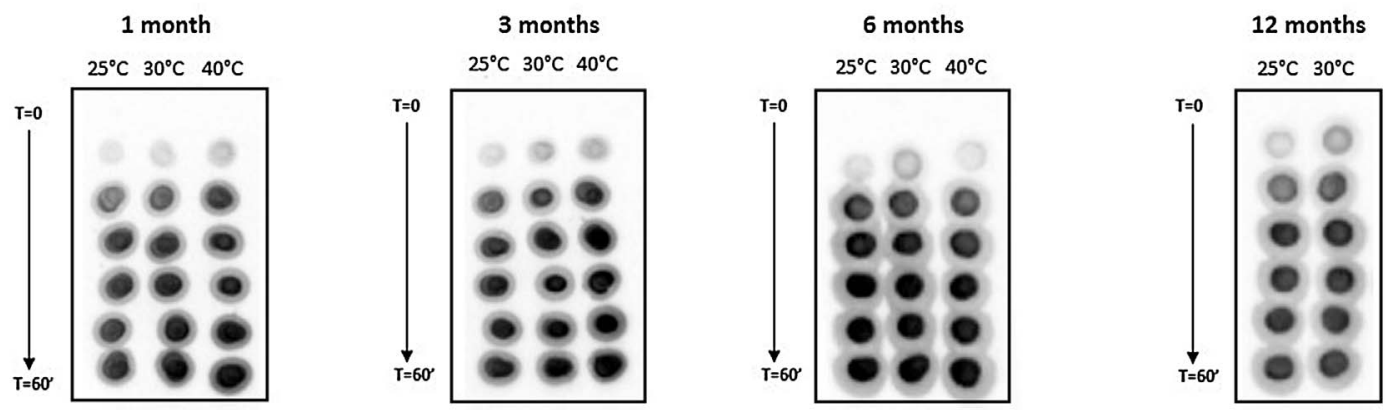

B.
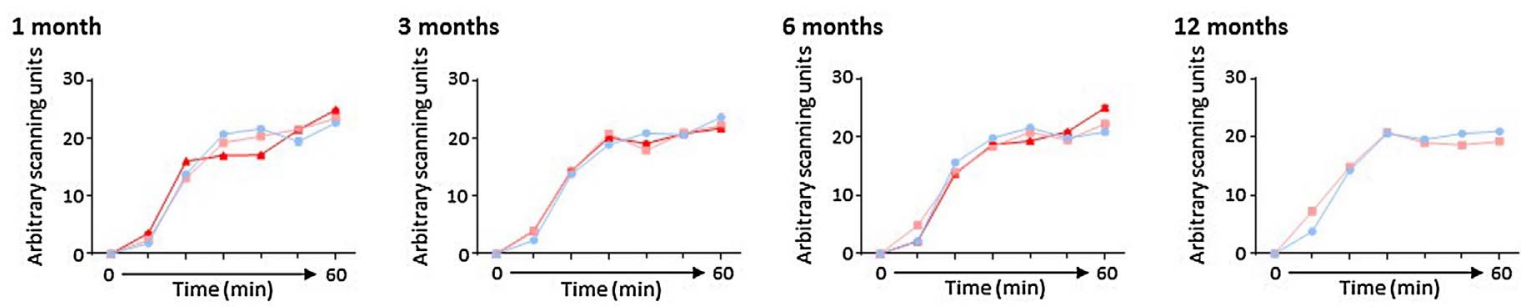

$-25^{\circ} \mathrm{C}-30^{\circ} \mathrm{C}-40^{\circ} \mathrm{C}$

Fig. 6. Antigen release is comparable in simulated intestinal fluid from SmPill minispheres exposed to various temperature and humidity conditions.

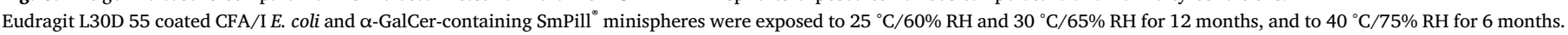

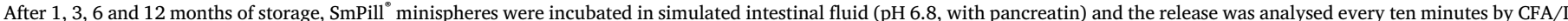

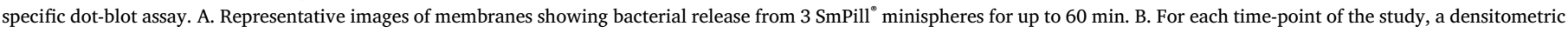

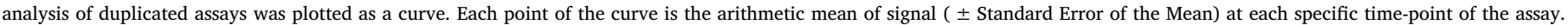

A.

\section{Eudragit L30D 55 coated SmPill ${ }^{\odot}$ minispheres in simulated gastric fluid}

\section{B. Eudragit L10055 + Opadry ${ }^{\circledast}$ White coated SmPill ${ }^{\odot}$ minispheres} in simulated gastric fluid

1 month

$25^{\circ} \mathrm{C} 30^{\circ} \mathrm{C} 40^{\circ} \mathrm{C}$

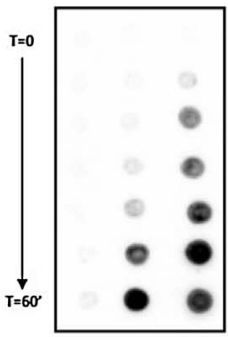

1 month

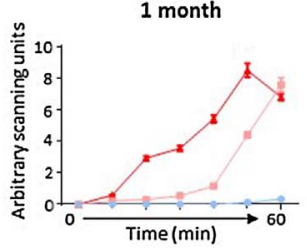

3 months

$25^{\circ} \mathrm{C} 30^{\circ} \mathrm{C} 40^{\circ} \mathrm{C}$

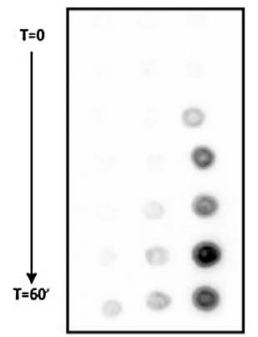

3 months

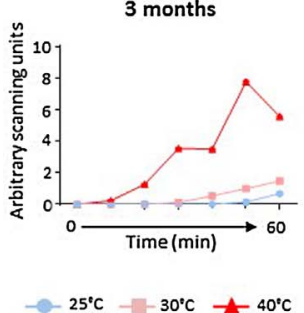

5 months
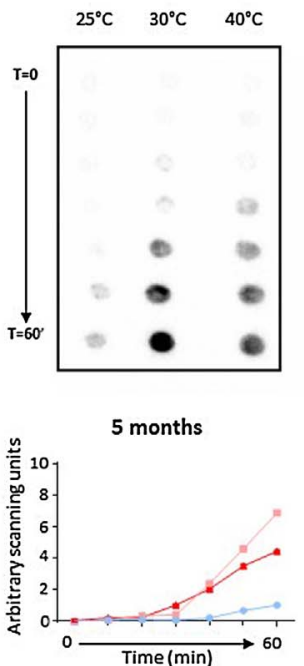

1 month
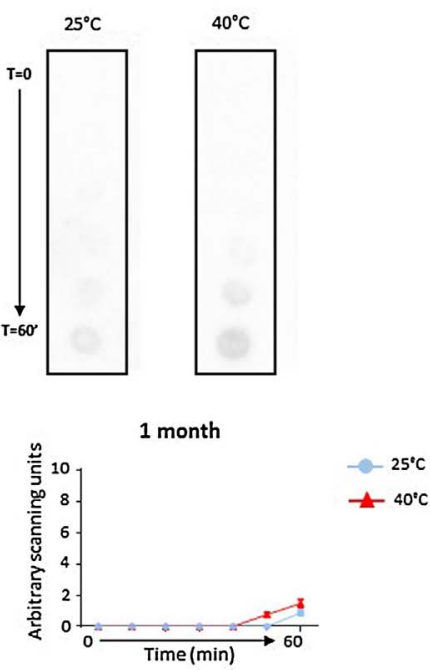

Fig. 7. Incorporation of an Opadry layer enhances antigen protection under gastric conditions in SmPill ${ }^{\circ}$ minispheres exposed to elevated temperature and humidity conditions.

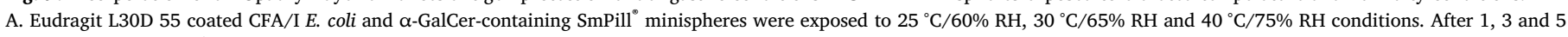

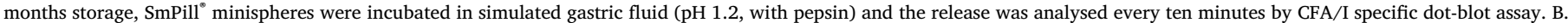

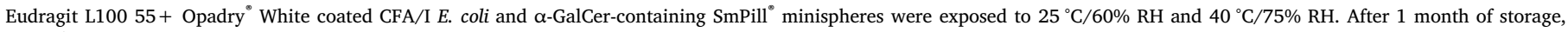

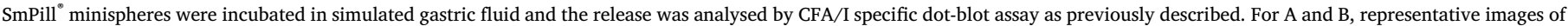

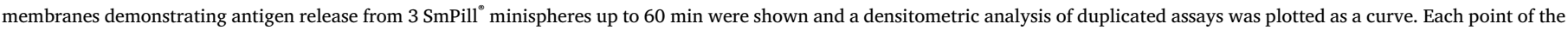
curve is the arithmetic mean of signal ( \pm Standard Error of the Mean) at each specific time-point of the assay. 

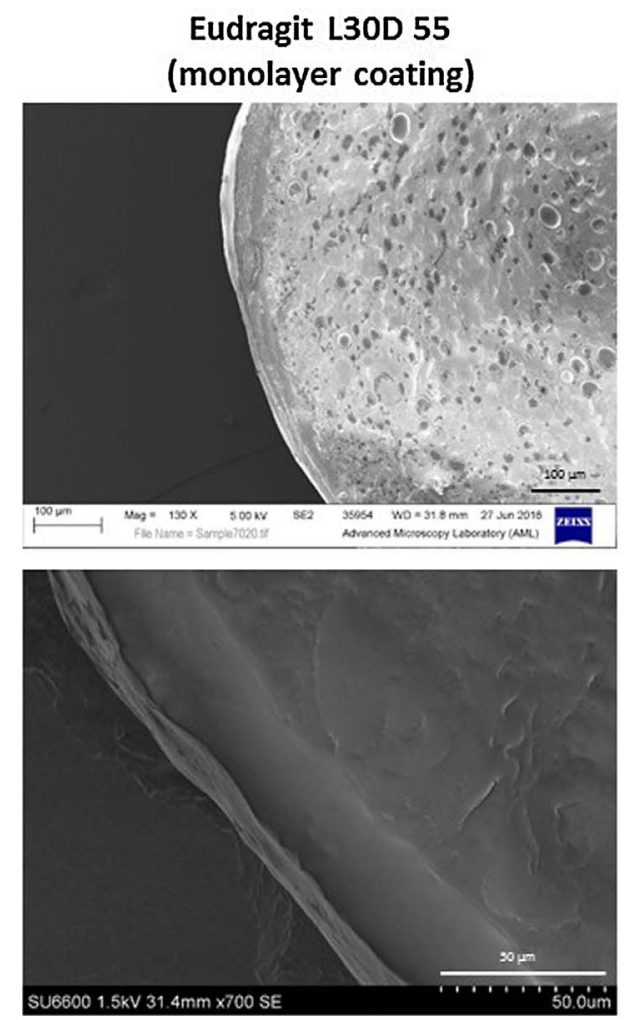

$\overline{\text { Eudragit L30D } 55}$

\section{Eudragit L100 55 + Opadry ${ }^{\circledR}$ White (double-layer coating)}
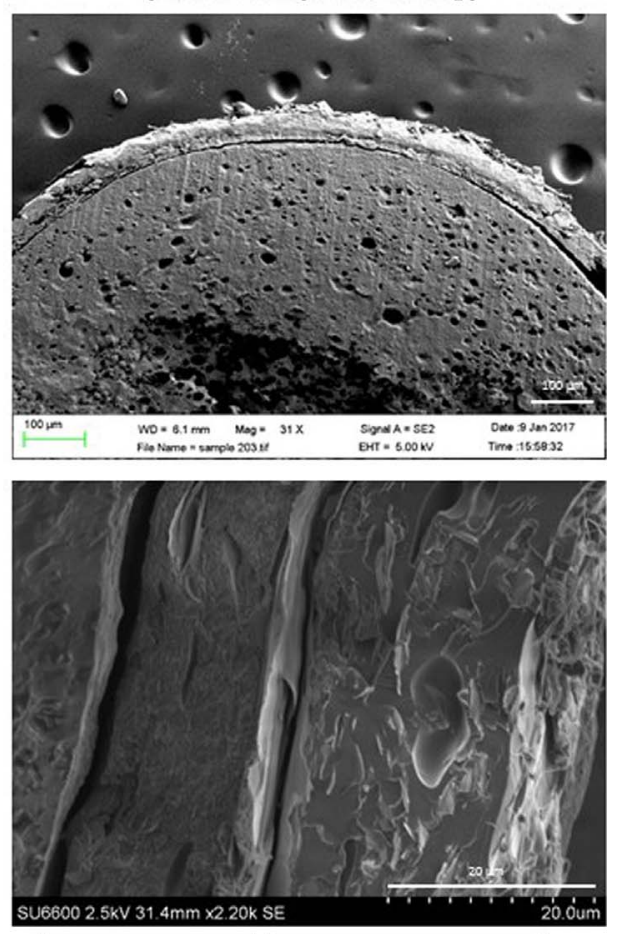

Opadry $^{\odot}$ White

Eudragit L100 55
Fig. 8. Visualization of Eudragit L30D 55 and Eudragit L100 55 + Opadry "White enteric coatings on SmPill minispheres.

The enteric coating of sectioned Eudragit L30D 55 coated SmPill minispheres and Eudragit L100 55+ Opadry ${ }^{\circ}$ White coated SmPill ${ }^{\circ}$ minispheres were analysed by SEM. Representative pictures of 3 SmPill ${ }^{\circ}$ minispheres per type of coating. Scale: $20-100 \mu \mathrm{m}$.

\section{Discussion}

The stability of a vaccine formulation is a key factor in the research, development and manufacturing processes. It is essential to establish that the materials can be stored under specified storage conditions for a specified period of time to address issues around quality, safety and efficacy (Schofield, 2009). Stability studies of intermediates may also help to adapt the formulation or to make modifications in manufacturing in order to improve stability properties. A novel integrated approach to oral vaccination using the SmPill ${ }^{\circ}$ technology was recently described to enhance the effectiveness of an ETEC candidate vaccine in a delivery system amenable to convenient and large scale administration to humans (Davitt et al., 2016). In this present study, we evaluated the stability of this enteric-coated delivery system containing a recombinant formalin-killed whole cell $E$. coli overexpressing CFA/I and the orally active adjuvant $\alpha$-GalCer.

The internal structure of SmPill ${ }^{\circledR}$ minispheres containing the vaccine formulation did not exhibit any visible changes when minispheres were exposed to $25^{\circ} \mathrm{C} / 60 \% \mathrm{RH}$ (normal condition) and $30^{\circ} \mathrm{C} / 65 \% \mathrm{RH}$ (intermediate condition) for up to 12 months, or to $40^{\circ} \mathrm{C} / 75 \% \mathrm{RH}$ (accelerated condition) for up to 6 months. Indeed the emulsion droplets and localisation of the antigen were comparable over time. The honeycomb hydrophilic gel structure is clearly maintained, the liquid phase droplets remain dispersed and well immobilised in the gelatin matrix, which is crucial. A modification of this structure could lead to a droplet instability and consequently to a SmPill ${ }^{\circ}$ minisphere deformation, antigen release modification as well as loss of antigen/adjuvant protection. Interestingly, similar results were observed in uncoated SmPill ${ }^{\circ}$ minispheres showing that the internal structure of the core itself is robust at elevated temperature and humidity. In addition, we found that the antigenicity of the SmPill vaccine formulations was preserved when SmPill ${ }^{\circ}$ minispheres were stored at $25{ }^{\circ} \mathrm{C} / 60 \% \mathrm{RH}$ and at $30{ }^{\circ} \mathrm{C}$ / $65 \% \mathrm{RH}$ for 12 months as well as at $40{ }^{\circ} \mathrm{C} / 75 \% \mathrm{RH}$ for 6 months. The preservation of CFA/I antigenicity is vital for the functionality of SmPill ${ }^{\oplus}$ minispheres. The maintenance of the internal matrix structure of the core helps to avoid degradation of the CFA/I antigen as it is protected inside the droplets. Furthermore, the immunostimulatory activity of the adjuvant $\alpha$-GalCer was also preserved in SmPill ${ }^{\circ}$ minispheres exposed to $25{ }^{\circ} \mathrm{C} / 60 \% \mathrm{RH}, 30^{\circ} \mathrm{C} / 65 \% \mathrm{RH}$ and $40{ }^{\circ} \mathrm{C} / 75 \% \mathrm{RH}$ for up to 5 months. One particularly important benefit of SmPill delivery system is the possibility to incorporate and subsequently deliver poorly water-soluble components such as cyclosporine (Keohane et al., 2016) or celecoxib (McDonald et al., 2015). The adjuvant $\alpha$-GalCer is a glycosphingolipid which is nearly insoluble in aqueous media. If $\alpha$-GalCer precipitates or crystallises and consequently loses its solubility, a reduction of its activity could be expected. The conservation of $\alpha$-GalCer activity is key for the functionality of the SmPill ${ }^{\circledR}$ delivery system. This results also demonstrates that the solubilisation of the adjuvant in Kolliphor HS 15 before incorporation inside SmPill ${ }^{\circ}$ minispheres maintains its solubility and subsequently its activity.

The sum of these results indicates that both the adjuvant and antigenic components are highly stable within this advanced vaccine formulation following storage at room temperature and also following storage at high temperatures.

Enteric coatings can be applied to SmPill ${ }^{\circ}$ formulations to facilitate site-specific release and minimize degradation under acidic conditions. Indeed, the formulation containing ETEC and $\alpha$-GalCer was designed to retain minisphere integrity in the stomach and facilitate antigen release in the small intestine, more specifically the jejunum, to trigger immune responses at the appropriate site for protection against ETEC infection. Anionic polymethacrylates are commonly used polymers to confer enteric properties. Eudragit is one of the most common pH-dependent coatings used. A wide range of Eudragit ${ }^{\circ}$ polymers with different dissolution properties have been developed (Nikam et al., 2011). Eudragit ${ }^{\circ}$ L30D 55 and L100 55 used to coat SmPill ${ }^{\circ}$ minispheres are soluble in intestinal fluid from pH 5.5. These specific polymers have been already used in various types of formulation such as enteric coated tablets, capsules, films, nano/microparticles and microspheres (Patra et al., 2017). One study analysed the impact of temperature and humidity on Eudragit ${ }^{\bullet}$ L30D 55 coated diclofenac pellets or capsules. Contrary to 
Hudovornik and colleagues (2015) (Hudovornik and Vrecer, 2015) who determined that high $\mathrm{RH}$ and temperature accelerated drug release from Eudragit ${ }^{\circ}$ L30D 55 coated diclofenac pellets, we found that bacterial release from SmPill ${ }^{\circ}$ is similarly preserved at $\mathrm{pH} 6.8$ when Eudragit ${ }^{\circ}$ L30D 55 coated SmPill ${ }^{\circ}$ were exposed to $25^{\circ} \mathrm{C} / 60 \% \mathrm{RH}$ and $30{ }^{\circ} \mathrm{C} / 65 \% \mathrm{RH}$ for 12 months, and at $40{ }^{\circ} \mathrm{C} / 75 \% \mathrm{RH}$ for 6 months. Interestingly, Pastor and coworkers developed cold chain free microparticles to deliver oral cholera vaccine and also used Eudragit L30 55 enteric coating. Their stability study performed under similar temperature and humidity conditions to our study showed a maintenance of Vibrio cholerae antigenicity and gastro-resistance even when the microparticles were exposed to extreme storage conditions (Pastor et al., 2013). In our study, it was also observed that Eudragit ${ }^{\circ}$ L30D 55 enteric coating of SmPill ${ }^{\circ}$ exposed to $25^{\circ} \mathrm{C} / 60 \%$ RH for 5 months remained stable at low $\mathrm{pH}$. The selectivity of the release is clearly maintained under these conditions. However, the stability of the Eudragit ${ }^{\circ}$ L30D 55 coating at low $\mathrm{pH}$ decreases following extended storage at $30{ }^{\circ} \mathrm{C} / 65 \% \mathrm{RH}$ and to a greater degree under $40{ }^{\circ} \mathrm{C} / 75 \% \mathrm{RH}$ conditions. The SEM evaluation of coated SmPill ${ }^{\oplus}$ minispheres allowed us to compare the modifications of the coating under each storage condition. The appearance of the enteric coating is maintained for up to 12 months at $25{ }^{\circ} \mathrm{C} / 60 \% \mathrm{RH}$. Minor microscopic differences reflected a small degree of variability in coating between the minispheres. However, the coating was clearly affected under intermediate and particularly under accelerated conditions. Indeed the minispheres were sticky, the coating thickness increased and was heterogenous around the minispheres. In addition, after 3 months, the colour of coated minispheres began to turn yellow and the surface became uneven. Morphological modifications of Eudragit L30D 55 coating is not uncommon upon long term storage under high temperature and humidity as already reported by Fan and colleagues who investigated the stability of Eudragit L30D 55 coated pellets containing tamsulosin hydrochloride (Fan et al., 2017).

In order to improve the appearance as well as to maintain the integrity and coating performance of the SmPill ${ }^{\circ}$ minispheres, an intermediate Opadry White film was introduced between the core and the enteric film. Opadry ${ }^{\circledR}$ has already been shown to be a very stable gastroresistant film in the context of Vitamin $\mathrm{B}_{2}$-containing pellets coated with this film and stored long term at $40{ }^{\circ} \mathrm{C}$ (Thoma and Bechtold, 1999). The preliminary data generated in our study demonstrate that this formulation strategy helps to prevent the stickiness of the minispheres and retain the performance of the enteric coating film when the formulation is stored at intermediate and accelerated conditions, and merits further characterisation through long term stability studies across a range of time-points and temperature and humidity conditions.

\section{Conclusions}

This study demonstrates the stability of an effective SmPill ${ }^{\circ}$ basedvaccine containing an adjuvanted ETEC candidate antigen and encourages follow up development work to progress this formulation into a clinical setting. Further parameters that will have to be examined include the impact of light on SmPill ${ }^{\circ}$ in order to determine the most suitable package and the usefulness of the system for incorporation of multiple vaccine components such as for a multivalent ETEC vaccine, the heat-labile toxin B subunit and other $E$. coli whole cells expressing other prevalent types of CFAs (Lundgren et al., 2014). However, this study provides evidence that the SmPill vaccine platform is compatible with storage at elevated temperature and humidity. Specifically, the data indicate that storage at $25^{\circ} / 60 \% \mathrm{RH}$ maintains CFA/I E. coli antigenicity, $\alpha$-GalCer immunostimulatory properties, SmPill ${ }^{\circ}$ internal structure and $\mathrm{pH}$-dependent antigen release. Under more extreme storage conditions, the stability of SmPill ${ }^{\circ}$ core was also confirmed in this study and the optimisation of coating layers to improve its integrity is continuously in progress to meet stability, storage and quality parameters required for clinical effects. The promising results of this study support continued development of the SmPill ${ }^{\circledR}$ oral vaccine system in efforts to address the high costs associated with maintenance of the cold chain during vaccine transport and storage (Mvundura et al., 2015; Kristensen et al., 2016) and to bring new highly needed products to the clinical development and finally the market.

\section{Competing financial interests}

ISC is CEO of Sigmoid Pharma Limited, a drug delivery company which holds the rights for the SmPill integrated drug delivery system used in this manuscript. All other authors have declared no conflicts of interest.

\section{Funding}

S.L is supported by the Swiss National Science Foundation [grant number P300PB-164740].

The work was supported by funding from Science Foundation Ireland (SFI) [grant number 12/IA/1421]; the SFI Research Centre, Advanced Materials and BioEngineering Research (AMBER) [grant number SFI/12/RC/2278]; and the European Union FP7 program HELICOVAXOR (2013) [grant number FP7-SME-2012-1 (Research For SMEs)] with co-funding from Sigmoid Pharma Limited.

\section{Acknowledgements}

We acknowledge the excellent technical support at the CRANN Advanced Microscopy Laboratory, TCD. Trinity Technology and Enterprise Campus, R802, Grand Canal Dock, Dublin, Ireland and the FOCAS Research Institute, Dublin Institute of Technology, Kevin Street, Dublin 8, Ireland.

We thank Prof. Ann-Mari Svennerholm (University of Gothenburg, Sweden) for kindly providing recombinant $E$. coli strain overexpressing CFA/I and anti-CFA/I mAbs.

We thank Mr. Peter O'Connell for his help to set up the stability studies in the School of Pharmacy and Pharmaceutical Sciences (Trinity College Dublin).

We thank Dr. Michael Parkinson (Dublin City University) for his help in statistical analysis of the data.

\section{Appendix A. Supplementary data}

Supplementary data associated with this article can be found, in the online version, at https://doi.org/10.1016/j.ijpharm.2017.10.013.

\section{References}

Aguirre, T.A., Rosa, M., Coulter, I.S., Brayden, D.J., 2015. In vitro and in vivo preclinical evaluation of a minisphere emulsion-based formulation (SmPill(R)) of salmon calcitonin. Eur. J. Pharm. Sci. 79, 102-111.

Aguirre, T.A., Teijeiro-Osorio, D., Rosa, M., Coulter, I.S., Alonso, M.J., Brayden, D.J., 2016. Current status of selected oral peptide technologies in advanced preclinical development and in clinical trials. Adv. Drug Deliv. Rev. 106, 223-241.

Ahren, C.M., Svennerholm, A.M., 1982. Synergistic protective effect of antibodies against Escherichia coli enterotoxin and colonization factor antigens. Infect. Immun. 38, 74-79.

Ando, T., Ito, H., Ohtaki, H., Seishima, M., 2013. Toll-like receptor agonists and alphagalactosylceramide synergistically enhance the production of interferon-gamma in murine splenocytes. Sci. Rep. 3, 2559.

Cerundolo, V., Barral, P., Batista, F.D., 2010. Synthetic iNKT cell-agonists as vaccine adjuvants-finding the balance. Curr. Opin. Immunol. 22, 417-424.

Cheng, A.C., McDonald, J.R., Thielman, N.M., 2005. Infectious diarrhea in developed and developing countries. J. Clin. Gastroenterol. 9, 757-773.

Czerkinsky, C., Holmgren, J., 2009. Enteric vaccines for the developing world: a challenge for mucosal immunology. Mucosal. Immunol. 2, 284-287.

Davitt, C.J., Lavelle, E.C., 2015. Delivery strategies to enhance oral vaccination against enteric infections. Adv. Drug Deliv. Rev. 91, 52-69.

Davitt, C.J., McNeela, E.A., Longet, S., Tobias, J., Aversa, V., McEntee, C.P., Rosa, M., Coulter, I.S., Holmgren, J., Lavelle, E.C., 2016. A novel adjuvanted capsule based strategy for oral vaccination against infectious diarrhoeal pathogens. J. Control. Release 233, 162-173.

Fan, R., Sun, Y., Li, B., Yang, R., Ma, W., Sun, J., 2017. Preparation and stability 
investigation of tamsulosin hydrochloride sustained release pellets containing acrylic resin polymers with two different techniques. Asian J. Pharm. Sci. 12, 193-201.

Girard, M.P., Steele, D., Chaignat, C.L., Kieny, M.P., 2006. A review of vaccine research and development: human enteric infections. Vaccine 24, 2732-2750.

Gupta, P.N., Khatri, K., Goyal, A.K., Mishra, N., Vyas, S.P., 2007. M-cell targeted biodegradable PLGA nanoparticles for oral immunization against hepatitis B. J. Drug Target. 15, 701-713.

Hudovornik, G., Vrecer, F., 2015. Impact of the curing parameters on drug release from Eudragit RS and RL 30D coated pellets: design of experiments. J. Drug Deliv. Sci. Technol. 30, 146-153.

Jansson, L., Tobias, J., Lebens, M., Svennerholm, A.M., Teneberg, S., 2006. The major subunit, $\mathrm{CfaB}$, of colonization factor antigen i from enterotoxigenic Escherichia coli is a glycosphingolipid binding protein. Infect. Immun. 74, 3488-3497.

Keohane, K., Rosa, M., Coulter, I.S., Griffin, B.T., 2016. Enhanced colonic delivery of ciclosporin a self-emulsifying drug delivery system encapsulated in coated minispheres. Drug Dev. Ind. Pharm. 42, 245-253.

Kohli, K., Chopra, S., Dhar, D., Arora, S., Khar, R.K., 2010. Self-emulsifying drug delivery systems: an approach to enhance oral bioavailability. Drug Discov. Today 15, 958-965.

Kristensen, D.D., Lorenson, T., Bartholomew, K., Villadiego, S., 2016. Can thermostable vaccines help address cold-chain challenges? Results from stakeholder interviews in six low- and middle-income countries. Vaccine 34, 899-904.

Lundgren, A., Bourgeois, L., Carlin, N., Clements, J., Gustafsson, B., Hartford, M., Holmgren, J., Petzold, M., Walker, R., Svennerholm, A.M., 2014. Safety and immunogenicity of an improved oral inactivated multivalent enterotoxigenic Escherichia coli (ETEC) vaccine administered alone and together with dmLT adjuvant in a doubleblind, randomized, placebo-controlled Phase I study. Vaccine 32, 7077-7084.

Marasini, N., Skwarczynski, M., Toth, I., 2014. Oral delivery of nanoparticle-based vaccines. Expert Rev. Vaccines 13, 1361-1376.

McDonald, B.F., Coulter, I.S., Marison, I.W., 2015. Microbeads: a novel multiparticulate drug delivery technology for increasing the solubility and dissolution of celecoxib. Pharm. Dev. Technol. 20, 211-218.

Mowat, A.M., Agace, W.W., 2014. Regional specialization within the intestinal immune system. Nat. Rev. Immunol. 14, 667-685.

Mvundura, M., Lorenson, K., Chweya, A., Kigadye, R., Bartholomew, K., Makame, M., Lennon, T.P., Mwangi, S., Kirika, L., Kamau, P., Otieno, A., Murunga, P., Omurwa, T., Dafrossa, L., Kristensen, D., 2015. Estimating the costs of the vaccine supply chain and service delivery for selected districts in Kenya and Tanzania. Vaccine 33, 2697-2703.

Nikam, V.K., Kotade, K.B., Gaware, V.M., Dolas, R.T., Dhamak, K.B., Somwanshi, S.B., Khadse, A.N., Kashid, V.A., 2011. Eudragit a versatile polymer: a review. Pharmacologyonline 1, 152-164.

Pastor, M., Esquisabel, A., Talavera, A., Ano, G., Fernandez, S., Cedre, B., Infante, J.F., Callico, A., Pedraz, J.L., 2013. An approach to a cold chain free oral cholera vaccine: in vitro and in vivo characterization of Vibrio cholerae gastro-resistant microparticles.
Int. J. Pharm. 448, 247-258.

Patra, C.N., Priya, R., Swain, S., Jena, G.K., Panigrahi, K.C., Ghose, D., 2017. Pharmaceutical significance of eudragit: a review. Future J. Pharm. Sci. 3, 33-45.

Petri Jr., W.A., Miller, M., Binder, H.J., Levine, M.M., Dillingham, R., Guerrant, R.L., 2008. Enteric infections, diarrhea, and their impact on function and development. J. Clin. Invest. 118, 1277-1290.

Qadri, F., Svennerholm, A.M., Faruque, A.S., Sack, R.B., 2005. Enterotoxigenic Escherichia coli in developing countries: epidemiology, microbiology, clinical features, treatment, and prevention. Clin. Microbiol. Rev. 18, 465-483.

Qadri, F., Saha, A., Ahmed, T., Al Tarique, A., Begum, Y.A., Svennerholm, A.M., 2007. Disease burden due to enterotoxigenic Escherichia coli in the first 2 years of life in an urban community in Bangladesh. Infect. Immun. 75, 3961-3968.

Rhee, J.H., Lee, S.E., Kim, S.Y., 2012. Mucosal vaccine adjuvants update. Clin. Exp. Vaccine Res. 1, 50-63.

Schofield, T.L., 2009. Vaccine stability study design and analysis to support product licensure. Biologicals 37, 387-396 Discussion 421-383.

Stability Testing of New Drug Substances and Products ICH Topic Q 1A (R2) European Medicines Agency Quality Guidelines ICH.

Svennerholm, A.M., Vidal, Y.L., Holmgren, J., McConnell, M.M., Rowe, B., 1988. Role of PCF8775 antigen and its coli surface subcomponents for colonization, disease, and protective immunogenicity of enterotoxigenic Escherichia coli in rabbits. Infect. Immun. 56, 523-528.

Tambuwala, M.M., Manresa, M.C., Cummins, E.P., Aversa, V., Coulter, I.S., Taylor, C.T., 2015. Targeted delivery of the hydroxylase inhibitor DMOG provides enhanced efficacy with reduced systemic exposure in a murine model of colitis. J. Control. Release 217, 221-227.

Thoma, K., Bechtold, K., 1999. Influence of aqueous coatings on the stability of enteric coated pellets and tablets. Eur. J. Pharm. Biopharm. 47, 39-50.

Tobias, J., Svennerholm, A.M., 2012. Strategies to overexpress enterotoxigenic Escherichid coli (ETEC) colonization factors for the construction of oral whole-cell inactivated ETEC vaccine candidates. Appl. Microbiol. Biotechnol. 93, 2291-2300.

Tobias, J., Lebens, M., Bolin, I., Wiklund, G., Svennerholm, A.M., 2008. Construction of non-toxic Escherichia coli and Vibrio cholerae strains expressing high and immunogenic levels of enterotoxigenic E. coli colonization factor I fimbriae. Vaccine 26 , 743-752.

Walker, R.I., Clifford, A., 2015. Recommendations regarding the development of combined enterotoxigenic Eschericha coli and Shigella vaccines for infants. Vaccine 33, 946-953.

Walker, R.I., Steele, D., Aguado, T., Ad Hoc, E.T.E.C., 2007. Analysis of strategies to successfully vaccinate infants in developing countries against enterotoxigenic $E$. coli (ETEC) disease. Vaccine 25, 2545-2566.

Wang, S., Liu, H., Zhang, X.F., 2015. Qian Intranasal and oral vaccination with proteinbased antigens: advantages challenges and formulation strategies. Protein Cell 6, 480-503. 